OPEN ACCESS

Edited by:

Verena Tretter,

Medizinische Universität Wien,

Austria

Reviewed by:

Laura Maria Frago,

Universidad Autónoma de Madrid,

Spain

Pere Garriga

Universitat Politecnica de Catalunya,

Spain

${ }^{*}$ Correspondence:

Flora de Pablo

fdepablo@cib.csic.es

Enrique J. de la Rosa

ejdelarosa@cib.csic.es

Received: 21 September 2018 Accepted: 02 November 2018

Published: 26 November 2018

Citation:

de Pablo F, Hernández-Sánchez C and de la Rosa EJ (2018) The

Prohormone Proinsulin as a

Neuroprotective Factor: Past History and Future Prospects.

Front. Mol. Neurosci. 11:426. doi: 10.3389/fnmol.2018.00426

\section{The Prohormone Proinsulin as a Neuroprotective Factor: Past History and Future Prospects}

\author{
Flora de Pablo ${ }^{1,2 *}$, Catalina Hernández-Sánchez ${ }^{1,2}$ and Enrique J. de la Rosa ${ }^{1 *}$ \\ ${ }^{1} 3 \mathrm{D}$ Lab, Development, Differentiation and Degeneration, Centro de Investigaciones Biológicas, Consejo Superior de \\ Investigaciones Cientificas (CIB/CSIC), Madrid, Spain, ${ }^{2}$ Centro de Investigación Biomédica en Red de Diabetes y \\ Enfermedades Metabólicas Asociadas (CIBERDEM), ISCIII, Madrid, Spain
}

Proinsulin was first identified as the primary translation product of the insulin gene in Donald Steiner's laboratory in 1967, and was the first prohormone to be isolated and sequenced. While its role as an insulin precursor has been extensively studied in the field of endocrinology, the bioactivity of the proinsulin molecule itself has received much less attention. Insulin binds to isoforms A and B of the insulin receptor (IR) with high affinity. Proinsulin, in contrast, binds with high affinity only to IR-A, which is present in the nervous system, among other tissues and elicits antiapoptotic and neuroprotective effects in the developing and postnatal nervous system. Proinsulin specifically exerts neuroprotection in the degenerating retina in mouse and rat models of retinitis pigmentosa $(\mathrm{RP})$, delaying photoreceptor and vision loss after local administration in the eye or systemic (intramuscular) administration of an adeno-associated viral (AAV) vector that induces constitutive proinsulin release. AAV-mediated proinsulin expression also decreases the expression of neuroinflammation markers in the hippocampus and sustains cognitive performance in a mouse model of precocious brain senescence. We have therefore proposed that proinsulin should be considered a functionally distinct member of the insulin superfamily. Here, we briefly review the legacy of Steiner's research, the neural expression of proinsulin, and the tissue expression patterns and functional characteristics of IR-A. We discuss the neuroprotective activity of proinsulin and its potential as a therapeutic tool in neurodegenerative conditions of the central nervous system, particularly in retinal dystrophies.

Keywords: proinsulin, insulin receptor isoforms, IR-A, neuroretina, photoreceptors, retinitis pigmentosa, neurodegeneration, neuroprotection

\section{THE DISCOVERY OF PROINSULIN}

A seminal 1967 article (Steiner et al., 1967) describing proinsulin biosynthesis introduced this molecule as a paradigm of precursor protein production and processing. The authors demonstrated that the mature insulin molecule consists of two polypeptidic chains (designated A and B) joined by two disulfide bonds, plus an intrachain disulfide bond in chain A. These two chains, and the cleaved $\mathrm{C}$-peptide, are generated in the pancreas by specific proteolytic processing of the single-chain precursor molecule, proinsulin, by cellular proprotein convertases. Low levels of unprocessed proinsulin were subsequently described in circulating plasma (Melani et al., 1970). The discovery and characterization of the biochemical features of proinsulin brought about a marked change in the general understanding of hormone and neuropeptide biosynthesis (reviewed in Steiner, 2011). 
This foundational research on proinsulin and convertases (Rouillé et al., 1995) has had a long-lasting impact on protein crystallography and the understanding of the relationship between protein sequence, structure, folding and function. The impact of Steiner's proinsulin findings, as well as his pioneering studies on the evolutionary biology of insulin-like proteins, are summarized in an article (Weiss and Chan, 2015) commemorating his contributions to science published shortly after his death in 2014.

The discovery of proinsulin represents an important milestone in peptidic hormone biology (Rholam and Fahy, 2009). Steiner's descriptions of proinsulin synthesis and processing and the regulation of insulin secretion by pancreatic beta cells form the basis for our current understanding of prohormone storage in secretory granules and secretagogue-induced release (Steiner et al., 2009). Indeed, similar processes have since been described in other glands. Shortly after the discovery of proinsulin, Moore and colleagues showed that introduction of proinsulin cDNA into a cell lacking secretory machinery (e.g., a fibroblast) led to the secretion of proinsulin only; the fibroblasts did not store the protein and the secretion rate was constitutive and unaffected by secretagogues (Moore et al., 1983). Interestingly, in all species tested the plasma half-life of proinsulin was more than twice that of insulin, and minimal conversion of proinsulin to insulin or other intermediate forms occurred outside the pancreas (Robbins et al., 1984). Subsequent studies confirmed that the processing of other protein precursors, including proglucagon, prosomatostatin and proopiomelanocortin, was dependent on cell-specific expression of the corresponding prohormones and their convertases, and on trafficking via the secretory pathway (Douglass et al., 1984; Rholam and Fahy, 2009).

\section{PREPANCREATIC AND EXTRAPANCREATIC EXPRESSION OF THE INSULIN GENE}

For several decades it remained unclear whether the insulin gene (which we will refer as the "proinsulin gene") was expressed in extrapancreatic tissues (Eng and Yalow, 1981; Kojima et al., 2006) or before pancreatic differentiation in embryos (de Pablo et al., 1990; de Pablo and de la Rosa, 1995; Morales et al., 1997). Experiments in developing chicks and mice provided evidence of gene expression in nonpancreatic tissues, suggesting that proinsulin could be secreted and act as a signaling factor (Hernández-Sánchez et al., 2006).

Since the 1970s, studies have described the extrapancreatic expression of proinsulin/insulin, particularly in the nervous system. Jesse Roth's research group conducted pioneering work that demonstrated insulin immunoreactivity in rat brain (Havrankova et al., 1978), a finding supported by a later study showing that insulin binds to the abundant insulin receptors (IRs) in brain (Schwartz et al., 1992). Not until several years later was it shown that brain proinsulin/insulin expression is a consequence of neuronal expression of the proinsulin gene; cells containing proinsulin mRNA were identified in the periventricular area of the rat brain (Young, 1986) and in neurons (Devaskar et al., 1994). Extensive studies in chick embryos revealed developmentally regulated proinsulin mRNA expression during gastrulation and neurulation, in the neuroretina during proliferation and differentiation, and in the embryonic brain, liver and eye (Hernández-Sánchez et al., 1995; Morales et al., 1997; Alarcón et al., 1998). Translation of prepancreatic proinsulin mRNA was found to be tightly controlled in the chick (Hernández-Sánchez et al., 2003), and the low levels of protein produced remained as unprocessed proinsulin (Hernández-Sánchez et al., 1995; Alarcón et al., 1998) and were rapidly secreted. An even more complex situation was uncovered in the developing heart in chick embryos, where expression levels of the translationally active proinsulin transcript (Pro 1B) were much lower than in the neurulating embryo, and an intron-retaining variant with lower translation capacity predominated (Martínez-Campos et al., 2013). Indeed, we found that Pro 1B overexpression, which presumably increases proinsulin signaling in the embryo, led to abnormal cardiac morphogenesis. This finding underscores the importance of strict control of embryonic proinsulin expression and suggests a possible role of proinsulin as a key signaling factor. Proinsulin mRNA has also been detected from embryonic day (E) 13.5 to E18.5 in the mouse retina, and exogenous proinsulin shown to be as effective as insulin or IGF-I in decreasing apoptotic cell death in cultured retinas (Valenciano et al., 2006).

Insulin-like peptides emerged early in evolution. Chan and Steiner (2000) conducted a thorough analysis of the phylogenetic origin of the proinsulin gene and reported its presence in insects, mollusks and nematodes, among other multicellular species. Given their absence in the yeast genome, members of the family of insulin-like factor genes appear to have co-evolved with the appearance of the metazoan branch (Chervitz et al., 1998). As discussed in our review of proinsulin and insulin-like peptides in neural development (de la Rosa and de Pablo, 2011), a remarkable eight insulin-like genes are found in D. melanogaster (Nässel and Vanden Broeck, 2016), with cell and stage-specific patterns of expression, and 40 such genes in C. elegans (Li et al., 2003; Cornils et al., 2011).

\section{IR-A, A PROINSULIN RECEPTOR: EXPRESSION AND SIGNALING IN THE NERVOUS SYSTEM}

The IR is a membrane-bound receptor found in all vertebrate cells, and has an $\alpha_{2}-\beta_{2}$ tetrameric structure and intrinsic tyrosine kinase activity. Key mediators of the intracellular effects of insulin include the adaptor proteins IR substrates (IRSs), the lipid kinase PI3K, and the serine/threonine kinase AKT. For a comprehensive overview of the signaling properties of the IR, see Haeusler et al. (2018).

Alternative splicing of IR gene gives rise to two isoforms, $\mathrm{A}$ and $\mathrm{B}$; exon 11, which encodes 12 amino acids, is only found in IR-B (Figure 1A). These isoforms differ in terms of tissue distribution and signaling properties, their expression 
A

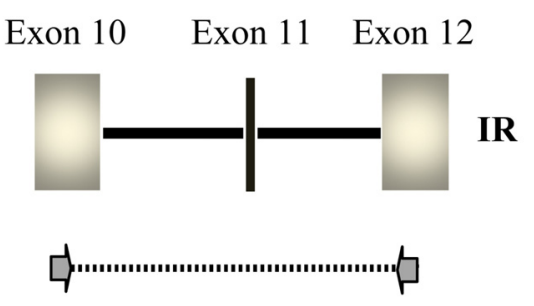

B Mouse tissues

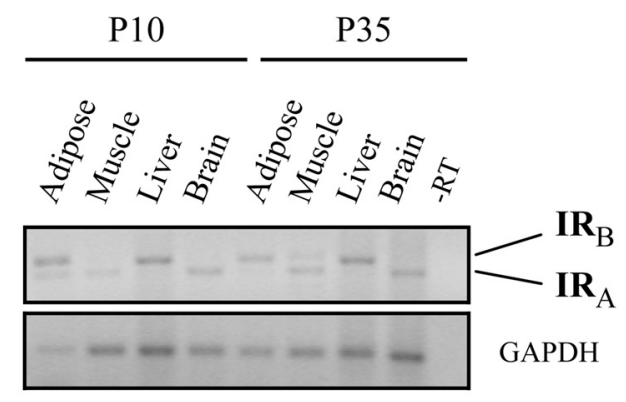

FIGURE 1 | Isoforms of the insulin receptor (IR) expressed in different tissues. (A) Schematic representation of the mammalian IR gene, exons 10-12. Exon 11 (in black vertical line) is spliced out during RNA processing in certain tissues. Primers used in the PCR shown in (B) are indicated with arrows. (B) IR-specific RT-PCR of RNA from the indicated mouse tissues at postnatal day 10 (P10) and P35. The positions of the amplified fragments corresponding to isoforms $A$ and $B$ of the IR are indicated. Note that only the IR-A isoform is expressed in the brain at both time points, whereas the IR-B isoform is expressed in the liver (figure adapted from Hernández-Sánchez et al., 2008).

is tightly regulated and play distinct roles in controlling cell functions (Vienberg et al., 2011). IR-A is the predominant or exclusive form expressed in mammalian fetal tissues, stem cells and adult brain, whereas it is expressed together with IR-B in variable proportion in other tissues (reviewed extensively in Belfiore et al., 2017). In the liver, IRs (mainly IR-B) are involved in regulating metabolism and show a reduced affinity for proinsulin (reviewed in Belfiore et al., 2009), in good agreement with the low metabolic potency of proinsulin (Galloway et al., 1992). Until recently, it was unclear which receptor type mediated the cell pro-survival effects of proinsulin. Studies of cellular expression of IR isoforms A and B revealed that IR-A mediates the downstream cellular effects of proinsulin. Indeed, in cultured cells nanomolar concentrations of proinsulin resulted in comparable stimulation of IR-A phosphorylation and ERK pathway activation to those of insulin (Malaguarnera et al., 2012; Belfiore et al., 2017). Those authors also reported that proinsulin resulted in lesser activation of AKT and failed to bind to IGF-I receptors or hybrid IR/IGF-IR receptors. That proinsulin does not bind to IGF-I receptors in human tissues is well demonstrated (Burguera et al., 1991), and has important implications for proinsulin-based therapies, decreasing the potential unwanted side effects, as discussed further below. In recent studies, dysregulation of the ratio of
IR-A/IR-B in various tissues has been associated with insulin resistance, aging and increased proliferative activity (Belfiore et al., 2017).

Remarkably, IR-A, which binds IGF-II with a similar affinity to insulin, is evolutionarily older than IR-B, which first appeared in the mammalian genome (Hernández-Sánchez et al., 2008). In the liver, IR-B is the predominantly expressed isoform, as stated above, whereas in adipose tissue and muscle intermediate expression levels of isoforms A and B are found (Belfiore et al., 2017). By contrast, IR-A is the only isoform expressed in neurons (reviewed in Gralle, 2017). Our studies have only detected expression of IR-A in mouse brain (Figure 1B) and since the retina is also part of the central nervous system, we suspect that it will be the predominant IR type found in this tissue.

IR has been visualized by immunohistochemistry in rods and cones and other cell layers of the mammalian retina (Rodrigues et al., 1988; Gosbell et al., 2002). However, available immunohistochemical reagents do not distinguish between the two IR isoforms, therefore specific studies at the mRNA level need to be performed. Widespread IR-A mRNA expression is observed from early proliferative stages onward in the developing chick embryo retina, in which splicing variants are absent (as in all non-mammalian species; de la Rosa et al., 1994; HernándezSánchez et al., 2008). Rajala and coworkers conducted specific functional studies of mammalian IR in photoreceptors (Rajala et al., 2008, 2009, 2013). In rod-specific IR knock-out mice they demonstrated reduced PI3K and AKT signaling in rod photoreceptors, and consequent impairment of retinal function and photoreceptor loss following exposure to bright light (Rajala et al., 2008). Moreover, they found that cultured retina photoreceptors from newborn IR knock-out mice exhibited abnormal development and differentiation, with disorganization of the actin and tubulin cytoskeleton leading to a wide axonal growth cone phenotype (Rajala et al., 2009), and that loss of PI3K signaling in cones resulted in cone degeneration (Rajala et al., 2013). It should be noted however that these studies did not identify the active IR ligand (or ligands) in mouse retina.

\section{NEUROPROTECTIVE EFFECTS OF PROINSULIN IN THE BRAIN AND THE RETINA}

Studies demonstrating higher concentrations of proinsulin and insulin in the brain than in plasma, as well as developmental regulation of IR expression from early embryogenesis, led researchers to suspect potential autocrine-paracrine effects of both hormones in the nervous system (reviewed in Hernández-Sánchez et al., 2006 and de la Rosa and de Pablo, 2011). Brain IR signaling is implicated in satiety, body temperature, reproductive function and aging in several species (Kitamura et al., 2003; Kenyon, 2011; Kleinridders et al., 2014; Ewald et al., 2018). The effect of insulin on neuronal plasticity, through regulation of the uptake, release, and degradation of dopamine and norepinephrine and control of postsynaptic receptor sensitivity (reviewed in Gralle, 2017), 


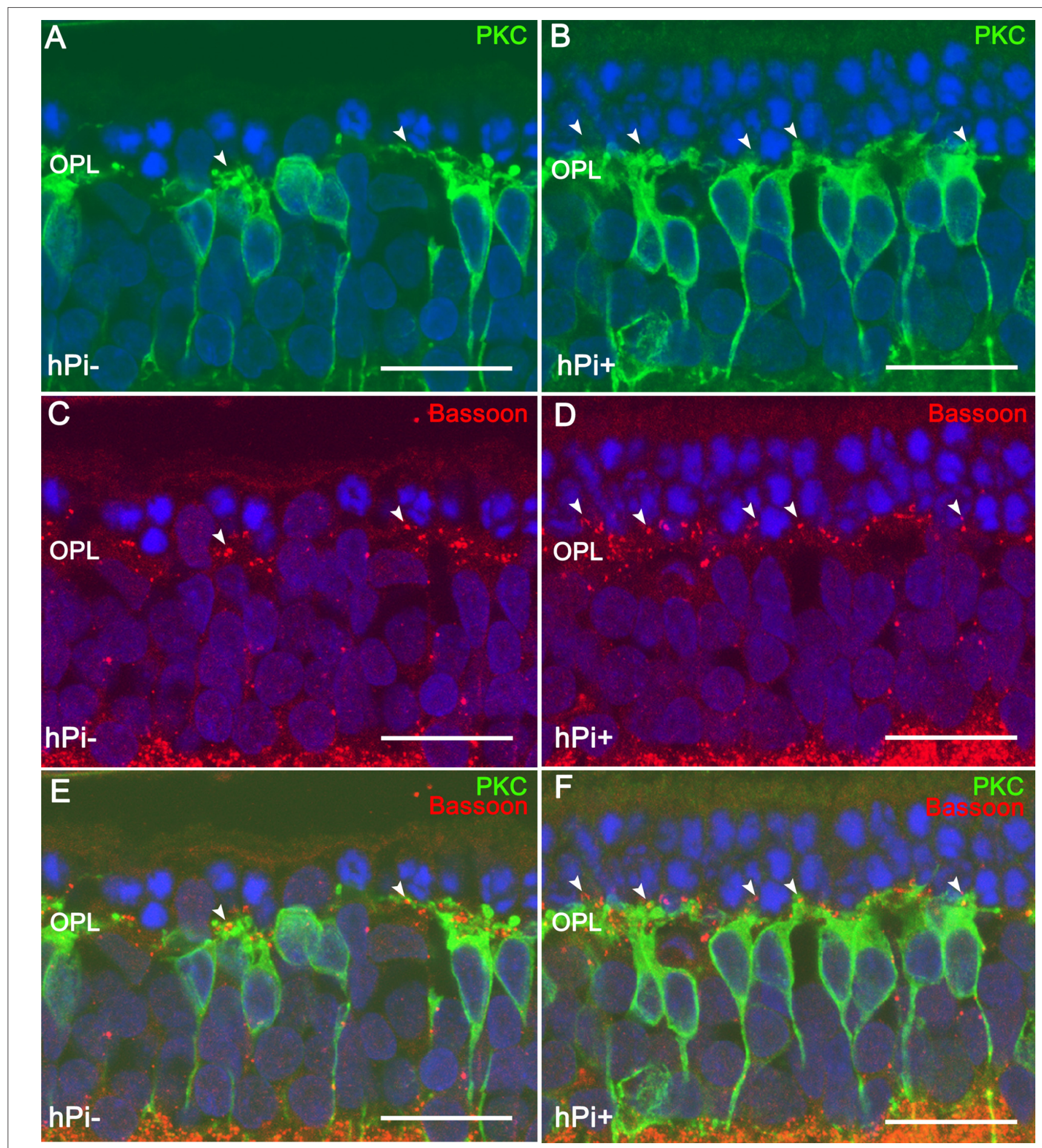

FIGURE 2 | Synaptic connectivity in the retinal outer plexiform layer (OPL) in untreated (hPi-) and proinsulin treated (hPi+) P23H rats. PKC (green) and Bassoon (red) immunostaining reveals preservation of the synaptic connections between the photoreceptors and the bipolar cells in retinas from hPi-treated animals (B, $\mathbf{D}, \mathbf{F})$ as compared with control rats (A,C,E). Arrowheads indicate cone photoreceptor contacts. Scale bar, $10 \mu \mathrm{m}$. Image courtesy of Prof. N. Cuenca reproduced from Fernández-Sánchez et al. (2012).

has attracted particular attention. There is abundant evidence indicating that disruption of insulin activity in the brain impairs neuronal function and synaptogenesis (Gralle, 2017).
Furthermore, roles for IR signaling in glial cell function (including microglia) have been proposed (Kleinridders et al., 2014). 
A number of abnormalities found in Alzheimer's disease (AD) have also been linked to an insulin resistant state, termed "type 3 diabetes" (de la Monte, 2017). Based on the work of multiple research groups conducted in animal models over several decades, an insulin-based therapy for this complex neurodegenerative process has been tested in clinical trials (de la Monte, 2017). Although genetic factors appear to influence the outcome, insulin therapy, particularly when administered intranasally, delayed progression of cognitive impairment in at least a subgroup of $\mathrm{AD}$ patients, although side effects in some patients included hypoglycemia. While few retinal studies have been conducted, stimulation of the insulin/mTOR pathway was found to delay cone cell death in a mouse model of retinitis pigmentosa (RP; Punzo et al., 2009). However, in most studies of the effects of insulin on the brain, little attention has been paid to the potential contributions of local proinsulin to the observed outcomes.

Given that expression of the proinsulin gene in the retina of chick embryos leads to production of unprocessed proinsulin (as stated above), and our previous findings demonstrating antiapoptotic effects of proinsulin, via PI3K activation, in mouse retinal cells (Valenciano et al., 2006), in our laboratory we have specifically focused on the potential neuroprotective effects of proinsulin. In a series of preclinical studies conducted using mouse and rat models over the last decade we have provided proof of concept for the use of proinsulin as neuroprotective agent in the treatment of retinal dystrophies, particularly RP (Corrochano et al., 2008; Fernández-Sánchez et al., 2012; Isiegas et al., 2016).

Inherited retinal dystrophies, including RP, can be caused by a wide variety of mutations in over 300 different genes. In $\mathrm{RP}$ in particular, the underlying mutation induces photoreceptor cell death, leading to progressive loss of visual function (Wert et al., 2014). The rd10 mouse, (Chang et al., 2007), is a useful model of autosomal recessive RP in which to assess the potential of proinsulin to attenuate disease progression. We showed that transgenesis of the human proinsulin gene into rd10 mice and its constitutive expression in muscle results in a modest systemic increase in proinsulin levels (low pM range), as well as delayed photoreceptor cell death and attenuated vision loss, as determined by electroretinography (Corrochano et al., 2008). Because this approach is not feasible in a clinical setting, we investigated alternative methods of proinsulin administration. Intraocular treatment of rd10 mice with biodegradable, proinsulin-loaded microbeads proved a successful delivery method, resulting in both cellular and functional neuroprotective effects. Electroretinography revealed increased amplitude of $b$-cone and mixed $b$-waves in proinsulintreated vs. control eyes. Moreover, proinsulin treatment attenuated photoreceptor cell loss, as determined by the thickness and number of cell rows in the outer nuclear cell layer (ONL) of the retina. Proinsulin also increased phosphorylation of $\mathrm{AKT}^{\mathrm{Thr} 308}$ in retinal explants from $\mathrm{rd} 10$ mice (Isiegas et al., 2016). In the P23H rat model of autosomal dominant RP, intramuscular injection of an Adeno-Associated Viral (AAV) vector expressing human proinsulin resulted in a significant elevation in levels of circulating proinsulin (with serum levels of 1.1-1.4 nM observed for at least 3 months post-injection; Fernández-Sánchez et al., 2012). The preservation of photoreceptor structure and function confirmed the neuroprotective effect of proinsulin in vivo. Moreover, proinsulin treated animals had $49 \%$ more photoreceptors than control animals, as well as better preserved synaptic contacts between photoreceptors and bipolar or horizontal cells (Figure 2). Thus, as we await the development of mutation-specific gene therapies, we propose that proinsulin be added to the list of factors that could potentially promote cell survival in retinal dystrophies (Kolomeyer and Zarbin, 2014).

Based on the observation that neurodegenerative diseases of the brain and retina share several underlying pathological changes, including oxidative stress and neuroinflammation (Cuenca et al., 2014; de la Rosa and Hernández-Sánchez, 2019), we investigated the effects of injection of AAV vector bearing the human proinsulin gene in the SAMP8 mouse, a model of precocious brain senescence that exhibits several Alzheimer's disease-like traits (Corpas et al., 2017). Proinsulin treatment activated the AKT pathway and decreased expression of neuroinflammation markers in the hippocampus 5 months after injection. Moreover, proinsulin-treated mice exhibited lower levels than untreated controls of TNF- $\alpha$, interleukin- $1 \beta$ and the antiprotease $\alpha 2$-macroglobulin in the hippocampus, as well as decreased GFAP immunoreactivity, which reduced astrocyte reactivity to control levels. Importantly, these neuroprotective effects correlated with improved cognitive performance in spatial and recognition tasks. Interestingly, in these mice the concentration of circulating proinsulin after a single injection of the AAV vector was rather low (13 pM), and glycemia was unchanged with respect to untreated animals. Moreover, the absence of detectable human insulin in the treated mice confirmed that conversion of proinsulin to insulin was minimal. It will be interesting to further study neuroinflammatory mechanisms involving microglial cells in physiological and pathological aging as well as in retinal dystrophy models, and the response to proinsulin treatment.

The observations recapitulated above support our view that proinsulin is a suitable neuroprotective therapy, with lower metabolic risks than insulin; in our studies there were no changes in mice or rats body weight or glycemia. In the only clinical trial conducted to date (Galloway et al., 1992), proinsulin was tested as a possible insulin agonist of intermediate-acting effect for the treatment of diabetes mellitus. Very high levels of serum proinsulin were reached (1.4-8 $\mathrm{nM}$, almost a 1,000-fold increase with respect to normal values), raising concerns of an increased risk of myocardial infarction which led to the disclaimer of the future use of proinsulin in that metabolic context. Interestingly, however, after 6 months of extreme hyperproinsulinemia, no progress of diabetic retinopathy was observed. In our own studies we showed that proinsulin exerts neuroprotective activity at much lower concentrations, starting at the low $\mathrm{pM}$ range (Corrochano et al., 2008; Corpas et al., 2017). Moreover, because neurons are postmitotic cells and proinsulin does not bind to the IGF-1 receptor, the likelihood of unwanted proliferative side 
effects is significantly reduced. In summary, proinsulin may constitute a safer alternative to insulin for activation of the IR-A pathway in the context of neuronal degeneration or aging, especially if administered directly to the retina or brain. Further clinical trials will be required to determine the appropriate dose for each condition and the optimal route of administration.

\section{FUTURE PROSPECTS}

To translate the experimental observations to the clinical practice, preclinical studies with proinsulin using larger and preferentially diurnal animal models of RP, possibly using local administration of AAV vector in the eye, will need to be conducted before clinical trials are feasible. The advantages of proinsulin vs. insulin (longer half-life, attenuated AKT activation, very low risk of hypoglycemic or proliferative secondary effects), and the availability of several delivery methods to reach the target cells, suggest a promising future for proinsulin as a neuroprotective factor in retinal neurodegenerative diseases. Two major drawbacks are the current lack of a commercial proinsulin preparation suitable for immediate testing and the requirement of GMP-level formulations for advanced preclinical studies. Lessons learned in studies of rare diseases such as RP may be useful in other contexts in which neuroprotection could be beneficial (e.g., the use of proinsulin in combination with other therapies, including mutation-specific gene therapy), paving the way for broader use

\section{REFERENCES}

Alarcón, C., Serna, J., Pérez-Villamil, B., and de Pablo, F. (1998). Synthesis and differentially regulated processing of proinsulin in developing chick pancreas, liver and neuroretina. FEBS Lett. 436, 361-366. doi: 10.1016/s00145793(98)01168-5

Belfiore, A., Frasca, F., Pandini, G., Sciacca, L., and Vigneri, R. (2009). Insulin receptor isoforms and insulin receptor/insulin-like growth factor receptor hybrids in physiology and disease. Endocr. Rev. 30, 586-623. doi: 10.1210/er. 2008-0047

Belfiore, A., Malaguarnera, R., Vella, V., Lawrence, M. C., Sciacca, L., Frasca, F., et al. (2017). Insulin receptor isoforms in physiology and disease: an updated view. Endocr. Rev. 38, 379-431. doi: 10.1210/er.2017-00073

Burguera, B., Frank, B. H., DiMarchi, R., Long, S., and Caro, J. F. (1991). The interaction of proinsulin with the insulin-like growth factor-I receptor in human liver, muscle, and adipose tissue. J. Clin. Endocrinol. Metab. 72, 1238-1241. doi: 10.1210/jcem-72-6-1238

Chan, S. J., and Steiner, D. F. (2000). Insulin through the ages: phylogeny of a growth promoting and metabolic regulatory hormone. Am. Zool. 40, 213-222. doi: $10.1093 / \mathrm{icb} / 40.2 .213$

Chang, B., Hawes, N. L., Pardue, M. T., German, A. M., Hurd, R. E., Davisson, M. T., et al. (2007). Two mouse retinal degenerations caused by missense mutations in the $\beta$-subunit of rod cGMP phosphodiesterase gene. Vision Res. 47, 624-633. doi: 10.1016/j.visres.2006.11.020

Chervitz, S. A., Aravind, L., Sherlock, G., Ball, C. A., Koonin, E. V., Dwight, S. S., et al. (1998). Comparison of the complete protein sets of worm and yeast: orthology and divergence. Science 282, 2022-2028. doi: 10.1126/science.282. 5396.2022

Cornils, A., Gloeck, M., Chen, Z., Zhang, Y., and Alcedo, J. (2011). Specific insulin-like peptides encode sensory information to regulate distinct developmental processes. Development 138, 1183-1193. doi: 10.1242/dev. 060905

Corpas, R., Hernández-Pinto, A. M., Porquet, D., Hernández-Sánchez, C., Bosch, F., Ortega-Aznar, A., et al. (2017). Proinsulin protects against of proinsulin in the treatment of a range of more common conditions such as in glaucoma or the inflammaging brain.

\section{AUTHOR CONTRIBUTIONS}

FP wrote the article. CH-S and ER contributed to the final revision and editing of the text and figures.

\section{FUNDING}

Studies of proinsulin in our laboratory have been funded by Ministerio de Economía, Industria y Competitividad, Gobierno de España (MINECO; SAF2013-41059-R and SAF2016-75681R) and CIBER de Diabetes y Enfermedades Metabólicas Asociadas (CIBERDEM), an initiative of the Instituto de Salud Carlos III, Ministerio de Ciencia, Innovación y Universidades, Spain.

\section{ACKNOWLEDGMENTS}

We wish to thank Dr. Teresa Suárez for fruitful discussions over the years, Dr. Noemí L. Alvarez Lindo for help with the bibliography, and former fellows of the laboratory for their contributions to the studies reviewed here. We acknowledge support of the publication fee by the CSIC Open Access Publication Support Initiative through its Unit of Information Resources for Research (URICI).

age-related cognitive loss through anti-inflammatory convergent pathways. Neuropharmacology 123, 221-232. doi: 10.1016/j.neuropharm.2017. 06.014

Corrochano, S., Barhoum, R., Boya, P., Arroba, A. I., Rodríguez-Muela, N., Gómez-Vicente, V., et al. (2008). Attenuation of vision loss and delay in apoptosis of photoreceptors induced by proinsulin in a mouse model of retinitis pigmentosa. Invest. Ophthalmol. Vis. Sci. 49, 4188-4194. doi: 10.1167/iovs. 08-2182

Cuenca, N., Fernández-Sánchez, L., Campello, L., Maneu, V., De la Villa, P., Lax, P., et al. (2014). Cellular responses following retinal injuries and therapeutic approaches for neurodegenerative diseases. Prog. Retin. Eye Res. 43, 17-75. doi: 10.1016/j.preteyeres.2014.07.001

de la Monte, S. M. (2017). Insulin resistance and neurodegeneration: progress towards the development of new therapeutics for Alzheimer's disease. Drugs 77, 47-65. doi: 10.1007/s40265-016-0674-0

de la Rosa, E. J., Bondy, C. A., Hernández-Sánchez, C., Wu, X., Zhou, J., López-Carranza, A., et al. (1994). Insulin and insulin-like growth factor system components gene expression in the chicken retina from early neurogenesis until late development and their effect on neuroepithelial cells. Eur. J. Neurosci. 6, 1801-1810. doi: 10.1111/j.1460-9568.1994. tb00573.x

de la Rosa, E. J., and de Pablo, F. (2011). Proinsulin: from hormonal precursor to neuroprotective factor. Front. Mol. Neurosci. 4:20. doi: 10.3389/fnmol.2011. 00020

de la Rosa, E. J., and Hernández-Sánchez, C. (2019). "CNS targets for the treatment of retinal dystrophies: a win-win strategy," in Therapies for Retinal Degeneration: Targetting Common Processes, eds E. J. de la Rosa and T. G. Cotter (Burlington House, UK: Royal Society of Chemistry), 61-75.

de Pablo, F., and de la Rosa, E. J. (1995). The developing CNS: a scenario for the action of proinsulin, insulin and insulin-like growth factors. Trends Neurosci. 18, 143-150. doi: 10.1016/0166-2236(95)93892-2

de Pablo, F., Scott, L. A., and Roth, J. (1990). Insulin and insulin-like growth factor I in early development: peptides, receptors and biological events. Endocr. Rev. 11, 558-577. doi: 10.1210/edrv-11-4-558 
Devaskar, S. U., Giddings, S. J., Rajakumar, P. A., Carnaghi, L. R., Menon, R. K., and Zahm, D. S. (1994). Insulin gene expression and insulin synthesis in mammalian neuronal cells. J. Biol. Chem. 269, 8445-8454.

Douglass, J., Civelli, O., and Herbert, E. (1984). Polyprotein gene expression: generation of diversity of neuroendocrine peptides. Annu. Rev. Biochem. 53, 665-715. doi: 10.1146/annurev.bi.53.070184.003313

Eng, J., and Yalow, R. S. (1981). Evidence against extrapancreatic insulin synthesis. Proc. Natl. Acad. Sci. U S A 78, 4576-4578. doi: 10.1073/pnas.78.7.4576

Ewald, C. Y., Castillo-Quan, J. I., and Blackwell, T. K. (2018). Untangling longevity, dauer and healthspan in Caenorhabditis elegans insulin/IGF-1signalling. Gerontology 64, 96-104. doi: 10.1159/000480504

Fernández-Sánchez, L., Lax, P., Isiegas, C., Ayuso, E., Ruiz, J. M., de la Villa, P., et al. (2012). Proinsulin slows retinal degeneration and vision loss in the $\mathrm{P} 23 \mathrm{H}$ rat model of retinitis pigmentosa. Hum. Gene. Ther. 23, 1290-1300. doi: 10.1089/hum.2012.067

Galloway, J. A., Hooper, S. A., Spradlin, C. T., Howey, D. C., Frank, B. H., Bowsher, R. R., et al. (1992). Biosynthetic human proinsulin. review of chemistry, in vitro and in vivo receptor binding, animal and human pharmacology studies, and clinical trial experience. Diabetes Care 15, 666-692. doi: 10.2337/diacare.15.5.666

Gosbell, A. D., Favilla, I., and Jablonski, P. (2002). The location of insulin receptors in bovine retina and isolated retinal cells. Clin. Exp. Ophthalmol. 30, 124-130. doi: 10.1046/j.1442-6404.2002.00499.x

Gralle, M. (2017). The neuronal insulin receptor in its environment. J. Neurochem. 140, 359-367. doi: 10.1111/jnc.13909

Haeusler, R. A., McGraw, T. E., and Accili, D. (2018). Biochemical and cellular properties of insulin receptor signalling. Nat. Rev. Mol. Cell Biol. 19, 31-44. doi: $10.1038 / \mathrm{nrm} .2017 .89$

Havrankova, J., Schmechel, D., Roth, J., and Brownstein, M. (1978). Identification of insulin in rat brain. Proc. Natl. Acad. Sci. U S A 75, 5737-5741. doi: 10.1073/pnas.75.11.5737

Hernández-Sánchez, C., López-Carranza, A., Alarcón, C., de La Rosa, E. J., and de Pablo, F. (1995). Autocrine/paracrine role of insulin-related growth factors in neurogenesis: local expression and effects on cell proliferation and differentiation in retina. Proc. Natl. Acad. Sci. U S A 92, 9834-9838. doi: 10.1073/pnas.92.21.9834

Hernández-Sánchez, C., Mansilla, A., de la Rosa, E. J., and de Pablo, F. (2006). Proinsulin in development: new roles for an ancient prohormone. Diabetologia 49, 1142-1150. doi: 10.1007/s00125-006-0232-5

Hernández-Sánchez, C., Mansilla, A., de la Rosa, E. J., Pollerberg, G. E., Martínez-Salas, E., and de Pablo, F. (2003). Upstream AUGs in embryonic proinsulin mRNA control its low translation level. EMBO J. 22, 5582-5592. doi: 10.1093/emboj/cdg515

Hernández-Sánchez, C., Mansilla, A., de Pablo, F., and Zardoya, R. (2008). Evolution of the insulin receptor family and receptor isoform expression in vertebrates. Mol. Biol. Evol. 25, 1043-1053. doi: 10.1093/molbev/msn036

Isiegas, C., Marinich-Madzarevich, J. A., Marchena, M., Ruiz, J. M., Cano, M. J., de la Villa, P., et al. (2016). Intravitreal injection of proinsulin-loaded microspheres delays photoreceptor cell death and vision loss in the rd10 mouse model of retinitis pigmentosa. Invest. Ophthalmol. Vis. Sci. 57, 3610-3618. doi: $10.1167 /$ iovs.16-19300

Kenyon, C. (2011). The first long-lived mutants: discovery of the insulin/IGF-1 pathway for ageing. Philos. Trans. R Soc. Lond. B Biol. Sci. 366, 9-16. doi: 10.1098/rstb.2010.0276

Kitamura, T., Kahn, C. R., and Accili, D. (2003). Insulin receptor knockout mice. Annu. Rev. Physiol. 65, 313-332. doi: 10.1146/annurev.physiol.65.092101. 142540

Kleinridders, A., Ferris, H. A., Cai, W., and Kahn, C. R. (2014). Insulin action in brain regulates systemic metabolism and brain function. Diabetes 63, 2232-2243. doi: 10.2337/db14-0568

Kojima, H., Fujimiya, M., Terashima, T., Kimura, H., and Chan, L. (2006). Extrapancreatic proinsulin/insulin-expressing cells in diabetes mellitus: is history repeating itself? Endocr. J. 53, 715-722. doi: 10.1507/endocrj.kr-84

Kolomeyer, A. M., and Zarbin, M. A. (2014). Trophic factors in the pathogenesis and therapy for retinal degenerative diseases. Surv. Ophthalmol. 59, 134-165. doi: 10.1016/j.survophthal.2013.09.004

Li, W., Kennedy, S. G., and Ruvkun, G. (2003). daf-28 encodes a C. elegans insulin superfamily member that is regulated by environmental cues and acts in the DAF-2 signaling pathway. Genes. Dev. 17, 844-858. doi: 10.1101/gad. 1066503

Malaguarnera, R., Sacco, A., Voci, C., Pandini, G., Vigneri, R., and Belfiore, A. (2012). Proinsulin binds with high affinity the insulin receptor isoform a and predominantly activates the mitogenic pathway. Endocrinology 153, 2152-2163. doi: 10.1210/en.2011-1843

Martínez-Campos, E., Hernández-SanMiguel, E., López-Sánchez, C., De Pablo, F., and Hernández-Sánchez, C. (2013). Alternative splicing variants of proinsulin mRNA and the effects of excess proinsulin on cardiac morphogenesis. FEBS Lett. 587, 2272-2277. doi: 10.1016/j.febslet.2013.05.060

Melani, F., Rubenstein, A. H., and Steiner, D. F. (1970). Human serum proinsulin. J. Clin. Invest. 49, 497-507. doi: 10.1172/JCI106259

Moore, H. P., Walker, M. D., Lee, F., and Kelly, R. B. (1983). Expressing a human proinsulin cDNA in a mouse ACTH-secreting cell. intracellular storage, proteolytic processing, and secretion on stimulation. Cell 35, 531-538. doi: 10.1016/0092-8674(83)90187-3

Morales, A. V., Serna, J., Alarcón, C., de la Rosa, E. J., and de Pablo, F. (1997). Role of prepancreatic (pro)insulin and the insulin receptor in prevention of embryonic apoptosis. Endocrinology 138, 3967-3975. doi: 10.1210/endo.138. 9.5396

Nässel, D. R., and Vanden Broeck, J. (2016). Insulin/IGF signaling in Drosophila and other insects: factors that regulate production, release and post-release action of the insulin-like peptides. Cell. Mol. Life Sci. 73, 271-290. doi: 10.1007/s00018-015-2063-3

Punzo, C., Kornacker, K., and Cepko, C. L. (2009). Stimulation of the insulin/mTOR pathway delays cone death in a mouse model of retinitis pigmentosa. Nat. Neurosci. 12, 44-52. doi: 10.1038/nn.2234

Rajala, A., Dighe, R., Agbaga, M. P., Anderson, R. E., and Rajala, R. V. (2013). Insulin receptor signaling in cones. J. Biol. Chem. 288, 19503-19515. doi: 10.1074/jbc.m113.469064

Rajala, A., Tanito, M., Le, Y. Z., Kahn, C. R., and Rajala, R. V. (2008). Loss of neuroprotective survival signal in mice lacking insulin receptor gene in rod photoreceptor cells. J. Biol. Chem. 283, 19781-19792. doi: 10.1074/jbc. m802374200

Rajala, R. V., Rajala, A., Brush, R. S., Rotstein, N. P., and Politi, L. E. (2009). Insulin receptor signaling regulates actin cytoskeletal organization in developing photoreceptors. J. Neurochem. 110, 1648-1660. doi: 10.1111/j.1471-4159.2009. 06262.x

Rholam, M., and Fahy, C. (2009). Processing of peptide and hormone precursors at the dibasic cleavage sites. Cell. Mol. Life Sci. 66, 2075-2091. doi: 10.1007/s00018-009-0007-5

Robbins, D. C., Tager, H. S., and Rubenstein, A. H. (1984). Biologic and clinical importance of proinsulin. N. Engl. J. Med. 310, 1165-1175. doi: 10.1056/nejm198405033101807

Rodrigues, M., Waldbillig, R. J., Rajagopalan, S., Hackett, J., LeRoith, D., and Chader, G. J. (1988). Retinal insulin receptors: localization using a polyclonal anti-insulin receptor antibody. Brain Res. 443, 389-394. doi: 10.1016/00068993(88)91639-3

Rouillé, Y., Duguay, S. J., Lund, K., Furuta, M., Gong, Q., Lipkind, G., et al. (1995). Proteolytic processing mechanisms in the biosynthesis of neuroendocrine peptides: the subtilisin-like proprotein convertases. Front. Neuroendocrinol. 16, 322-361. doi: 10.1006/frne.1995.1012

Schwartz, M. W., Figlewicz, D. P., Baskin, D. G., Woods, S. C., and Porte, D. Jr. (1992). Insulin in the brain: a hormonal regulator of energy balance. Endocr. Rev. 13, 387-414. doi: 10.1210/er.13.3.387

Steiner, D. F. (2011). On the discovery of precursor processing. Methods Mol. Biol. 768, 3-11. doi: 10.1007/978-1-61779-204-5_1

Steiner, D. F., Cunningham, D., Spigelman, L., and Aten, B. (1967). Insulin biosynthesis: evidence for a precursor. Science 157, 697-700. doi: 10.1126/science.157.3789.697

Steiner, D. F., Park, S. Y., Støy, J., Philipson, L. H., and Bell, G. I. (2009). A brief perspective on insulin production. Diabetes Obes. Metab. 11, 189-196. doi: 10.1111/j.1463-1326.2009.01106.x

Valenciano, A. I., Corrochano, S., de Pablo, F., de la Villa, P., and de la Rosa, E. J. (2006). Proinsulin/insulin is synthesized locally and prevents caspase- and cathepsin-mediated cell death in the embryonic mouse retina. J. Neurochem. 99, 524-536. doi: 10.1111/j.1471-4159.2006. 04043.x 
Vienberg, S. G., Bouman, S. D., Sørensen, H., Stidsen, C. E., Kjeldsen, T., Glendorf, T., et al. (2011). Receptor-isoform-selective insulin analogues give tissue-preferential effects. Biochem. J. 440, 301-308. doi: 10.1042/bj20110880

Weiss, M. A., and Chan, S. J. (2015). Remembering Donald F. Steiner. Front. Endocrinol. 6:57. doi: 10.3389/fendo.2015.00057

Wert, K. J., Lin, J. H., and Tsang, S. H. (2014). General pathophysiology in retinal degeneration. Dev. Ophthalmol. 53, 33-43. doi: 10.1159/000 357294

Young, W. S. 3rd (1986). Periventricular hypothalamic cells in the rat brain contain insulin mRNA. Neuropeptides 8, 93-97. doi: 10.1016/01434179(86)90035-1
Conflict of Interest Statement: The authors declare that part of the research was performed after they were founders and scientific advisors of the CIB-CSIC spinoff company ProRetina Therapeutics S.L. presently extinguished.

Copyright (c) 2018 de Pablo, Hernández-Sánchez and de la Rosa. This is an open-access article distributed under the terms of the Creative Commons Attribution License (CC BY). The use, distribution or reproduction in other forums is permitted, provided the original author(s) and the copyright owner(s) are credited and that the original publication in this journal is cited, in accordance with accepted academic practice. No use, distribution or reproduction is permitted which does not comply with these terms. 